\title{
Optimization on the High Precision 3D Seismic Acquisition Parameters in Leijia Tight Sandstone Oil Area
}

\author{
Haibo Wang1,2, Wei Zhang², Bing Liu², Qiwei Zou³, Guanhua Xiao², Meibin Tang², Hong Zhu², \\ Wenjing $\mathbf{L i}^{2}$ \\ ${ }^{1}$ School of Geophysics and Information Technology, China University of Geosciences, Beijing, China \\ ${ }^{2}$ BGP Inc., CNPC, Panjin, China \\ ${ }^{3}$ Liaohe Oil field, CNPC, Panjin, China \\ Email: wanghaibo004@qq.com
}

How to cite this paper: Wang, H.B., Zhang, W., Liu, B., Zou, Q.W., Xiao, G.H., Tang, M.B., Zhu, H. and Li, W.J. (2017) Optimization on the High Precision 3D Seismic Acquisition Parameters in Leijia Tight Sandstone Oil Area. International Journal of Geosciences, 8, 30-45. http://dx.doi.org/10.4236/ijg.2017.81003

Received: October 31, 2016

Accepted: January 19, 2017

Published: January 22, 2017

Copyright $\odot 2017$ by authors and Scientific Research Publishing Inc. This work is licensed under the Creative Commons Attribution International License (CC BY 4.0).

http://creativecommons.org/licenses/by/4.0/

\begin{abstract}
The main targets of seismic exploration research in Leijia carbonatite tight sandstone oil area of Liaohe depression are thin reservoirs prediction and minor faults identification, which is one of the important representatives of complex exploration objects in Liaohe depression. High precision 3D seismic exploration has significantly improved the ability of thin reservoirs prediction and minor faults identification of this area. Reducing the cost of high precision 3D seismic exploration through optimizing the acquisition parameters is very important for the next step exploration and development of Liaohe depression and similar areas. Based on high precision 3D seismic acquisition data in Leijia tight sandstone oil area, multiple sub-geometries are obtained with different bin sizes, different folds, different aspect ratio, different line intervals by extracting receiver points and shot points, and PSTM processing is performed respectively, obtained PSTM datasets of the sub-geometries, extract time slices, amplitude slices along the layer, coherent slices and so on. We evaluate the data results of the sub-geometries from the aspects of signalto-noise ratio, thin reservoirs resolution, acquisition footprint and so on. Considering the exploration cost and data effect of each sub-geometry, the optimal direction of the main parameters of high precision seismic exploration in Liaohe depression is put forward, and the acquisition effect of adjacent area by the optimized parameters is given.
\end{abstract}

\section{Keywords}

High Precision 3D, Acquisition Parameters Optimization, Fold, Bin Size, Aspect Ratio, Line Interval, Acquisition Footprint 


\section{Introduction}

"Two Wide and One High" (Wide azimuth, wide band and high density) seismic exploration technology is a high precision seismic exploration push out for solving complicated area exploration technology in recent years, which has carried out trial in the Caspian Sea region abroad [1], and in Junggar basin, Tarim basin, Liaohe depression of China [2] [3] [4] [5], and achieved good results. But sample density of the seismic acquisition geometry becomes higher and higher, such as the bin size becomes smaller and smaller, the line interval becomes smaller and smaller, and the fold becomes higher and higher. It is generally believed that the high sampling density will certainly be better for imaging, which may result in a waste of cost. It is necessary to study whether the continuous enhancement of the geometry parameters has much effect on the imaging of complex geological targets and whether there is the possibility of weakening.

Domestic and foreign scholars using the actual acquired seismic data to do degenerative processing analysis to study the impact of 3D acquisition parameters on the data imaging are rare. Wloszczowski [6] carried out degradation processing about maximum offset, folds using a real data from the North Sea, to evaluate the impact of geometry parameters changing on the influence of signal to noise ratio, wavelet consistency, target attribute maps and deep imaging. P. I. Pecholcs [7], decimating the line intervals of the original volume from $100 \mathrm{~m}$ to $200 \mathrm{~m}$ and $500 \mathrm{~m}$ using a real high density data from Saudi Arabia, clearly shows how seismic signal to noise ratio and resolution improves with finer spatial sampling. Yun Ling [8] [9] carried out degradation processing and comprehensive interpretation using a full azimuth acquisition data from Junggar basin of western China, indicates that the wide azimuth (aspect ratio is greater than 0.5) has better spatial imaging resolution than narrow azimuth on lithologic exploration. Wei Zhang [10] carried out degradation processing about bin size, the number of shot points and array length from a high resolution acquisition data from Junggar basin of western China, to evaluate the impact of these parameters on the final stack profile. Ying Xu [11] and Yunhong Zhu [12] carried out degradation processing from high precision acquisition data from Tahe oilfiled and Tazhong oilfiled of western China respectively, they both proposed suggestions on key acquisition parameters for the high-precision 3D seismic exploration of their own area.

Bohai Bay Basin in eastern China is an important oil and gas production base. The sedimentary tectonics of Bohai Bay Basin is totally different from western China, and the seismic and geological conditions vary greatly. The literatures on degradation processing of high precision seismic data acquired in eastern China were not found. Based on the high precision 3D data of Leijia area in Liaohe depression of Bohai Bay Basin, this paper carried out degradation processing such as bin size, fold, aspect ratio, line interval, etc, systematically compared the difference of signal to noise ratio, thin layer imaging, fault imaging, data continuity caused by the geometry parameter variations from prestack time migration profile, 
time slice, amplitude slices along the layer, coherence slices, etc., put forward the optimization direction of high precision seismic exploration key acquisition parameters in Liaohe depression, provides the guidance for the optimization of high precision seismic acquisition in Bohai Bay Basin similar regions.

\section{Trials and Analysis}

We performed degradation processing of bin size, fold, aspect ratio and line interval on the base of Leijia high precision acquisition data, discusses the acquisition parameters with high cost performance under the premise of satisfying the geological task requirements, economic and technological integration requirements, put forward the optimization of the geometry, to guide the next step acquisition solutions development.

\subsection{Original Geometry Analysis}

Leijia high precision $3 \mathrm{D}$ seismic acquisition geometry is $32 \mathrm{~L} \times 10 \mathrm{~S} \times 352 \mathrm{~T}$ orthogonal (Figure 1), bin size: $10 \mathrm{~m} \times 10 \mathrm{~m}$, fold: 256 , receiver line interval/shot line interval: $200 \mathrm{~m} / 220 \mathrm{~m}$, the maximum offset: $4743 \mathrm{~m}$; aspect ratio: 0.91 . Shooting with charge.

This geometry has the characteristics of small bin size, high fold, large aspect ratio, high fold, the azimuth and offset is evenly distributed, and can meet the requirement of degradation processing of bin size, fold, aspect ratio and so on. Through analysis the influence of different geometry parameters on the effect of prestack time migration processing to optimize the geometry parameters in the complex area of Liaohe depression. In order to meet the requirements of geological task under the premise of saving seismic acquisition cost, to achieve economic and technological integration.

\subsection{Degradation Processing Solutions}

According to the characteristics of the $3 \mathrm{D}$ acquisition geometry in the experimental area, design four sets of 6 trial geometries (Table 1). S0 is the original geometry. S1 to S5 are sub-geometries.

The first group of geometry is composed of S0 and S1 in the table, which used

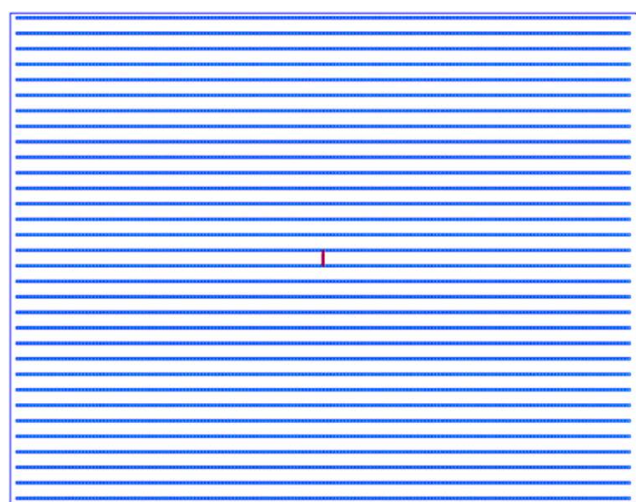

(a)

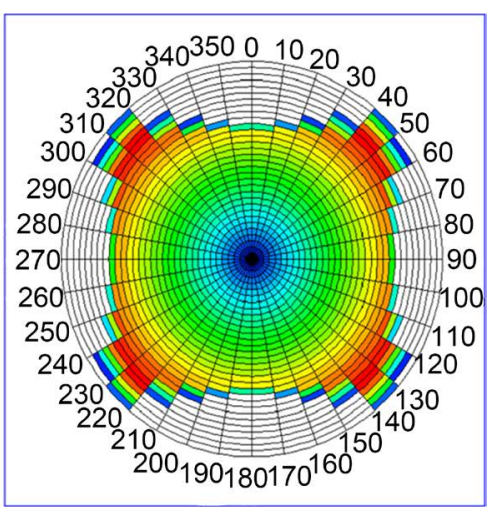

(b)

Figure 1. Geometry template (a) and rose diagram (b). 
Table 1. Degradation processing trial geometry parameters table.

\begin{tabular}{cccccccc}
\hline Parameters & geometry & $\begin{array}{c}\text { Bin size } \\
(\mathrm{m})\end{array}$ & $\begin{array}{c}\text { receiver } \\
\text { interval } \\
(\mathrm{m})\end{array}$ & $\begin{array}{c}\text { shot line } \\
\text { interval } \\
(\mathrm{m})\end{array}$ & fold & $\begin{array}{c}\text { trace } \\
\text { density } \\
\left(10^{4} / \mathrm{km}^{2}\right)\end{array}$ & $\begin{array}{c}\text { aspect } \\
\text { ratio }\end{array}$ \\
\hline S0 (original) & $32 \times 10 \mathrm{~S} \times 352 \mathrm{~T}$ & $10 \times 10$ & 200 & 220 & 256 & 256 & 0.91 \\
S1 & $32 \mathrm{~L} \times 5 \mathrm{~S} \times 176 \mathrm{~T}$ & $20 \times 20$ & 200 & 220 & 256 & 64 & 0.91 \\
S2 & $32 \mathrm{~L} \times 10 \mathrm{~S} \times 352 \mathrm{~T}$ & $10 \times 10$ & 200 & 440 & 128 & 128 & 0.91 \\
S3 & $16 \mathrm{~L} \times 10 \mathrm{~S} \times 352 \mathrm{~T}$ & $10 \times 10$ & 400 & 440 & 64 & 64 & 0.91 \\
S4 & $28 \mathrm{~L} \times 10 \mathrm{~S} \times 352 \mathrm{~T}$ & $10 \times 10$ & 200 & 220 & 224 & 224 & 0.80 \\
S5 & $16 \mathrm{~L} \times 10 \mathrm{~S} \times 352 \mathrm{~T}$ & $10 \times 10$ & 200 & 220 & 128 & 128 & 0.51 \\
\hline
\end{tabular}

for the bin size trial. Compared the PSTM processing results of different bin size $(10 \mathrm{~m} \times 10 \mathrm{~m}, 20 \mathrm{~m} \times 20 \mathrm{~m}$ ) with the same fold (256), to determine the appropriate bin size of this area. The bin size of $\mathrm{S} 1$ is $20 \mathrm{~m} \times 20 \mathrm{~m}$, extract one for two shot points in the crossline direction, and extract one for two receiver points in the inline direction, that is the shot point interval and receiver point interval from $20 \mathrm{~m}$ into $40 \mathrm{~m}$.

The second group of geometries is composed of S0, S2 and S3 in Table 1, which used for fold trial. Compared the PSTM processing results of different fold $(256,128,64)$ with the same bin size $(10 \mathrm{~m} \times 10 \mathrm{~m})$, to determine the appropriate fold of this area. S2 is based on the original geometry, extract one for two shot points in the inline direction, and the receiver point remains unchanged, that is the shot line interval from $220 \mathrm{~m}$ into $440 \mathrm{~m}$. S3 is based on S2, extract one for two receiver line, that is the shot line interval from $200 \mathrm{~m}$ into $400 \mathrm{~m}$.

The third group of geometries is composed of S1 and S3 in Table 1. Compared the PSTM processing results of different fold $(256,64)$ and different bin size $(20 \mathrm{~m} \times 20 \mathrm{~m}, 10 \mathrm{~m} \times 10 \mathrm{~m})$ with the same trace density $\left(64 \times 10^{4} / \mathrm{km}^{2}\right)$, to determine the appropriate fold of this area. $\mathrm{S} 2$ is based on the original geometry, extract one for two shot points in the inline direction and the receiving point remains unchanged, that is the shot line interval from $220 \mathrm{~m}$ into $440 \mathrm{~m}$. S3 is base on S2, extract one for two receiver lines, that is the receiver line interval from $200 \mathrm{~m}$ into $400 \mathrm{~m}$. The aim was to determine whether it would be more appropriate to use large bin size and high fold or small bin size and small fold acquisition under essentially the same workload.

The fourth group geometries is composed of S0, S4 and S5 in Table 1, and is used for aspect ratio trial, comparing with the same surface element $(10 \mathrm{~m} \times 10$ $\mathrm{m})$, and the processing effect of different aspect ratio $(0.91,0.80,0.51)$.

The fifth group geometries is composed of S0, S4 and S5 in Table 1, and is used to compared different receiver lines with the same bin size.

\subsection{Degradation Processing Flow}

Trial processing and analysis flow shown in Figure 2, mainly divided into fine 


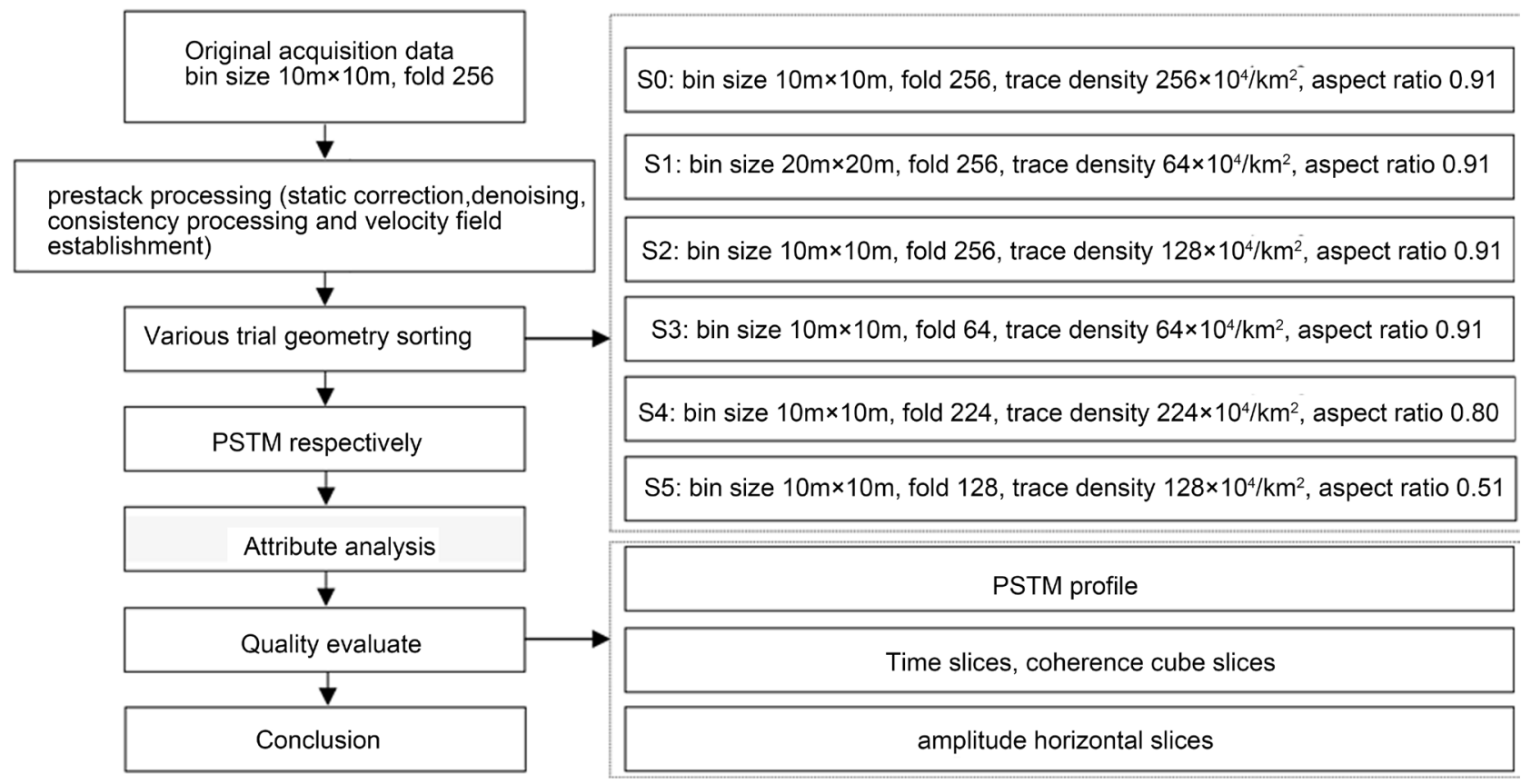

Figure 2. Trial processing and analysis flow.

prestack CMP gather processing and geometries degradation processing. The prestack processing is based on all the data of S0 geometry (bin size $10 \mathrm{~m} \times 10$ $\mathrm{m}$, fold 256) for a detailed processing parameters and flow testing. Include the following steps, (1) amplitude preserved denoising, cross domain adaptive surface wave attenuation to remove surface wave, fast and parallel frequency division to remove the abnormal amplitude, coherent noise attenuation to eliminate linear interference, and sub-azimuth high precision multi-wave attenuation in Radon domain; (2) the near surface correction, curved surface static correction, surface $\mathrm{Q}$ absorption compensation, not diagenetic medium absorption compensation; (3) Prestack spectral expansion of low frequency protection, low frequency protection based on wavelet transform; (4) the residual static correction and velocity analysis, improve the high frequency residual static correction accuracy, meanwhile, velocity field for stack and poststack migration trial is established, and the PSTM processing and multiple iterations of velocity analysis are processed with bin size $10 \mathrm{~m} \times 10 \mathrm{~m}$ is processed for all the prestack data after the prestack CMP gather processing, and established accurate PSTM velocity field, and all sub-geometries data are conducted PSTM processing using the above velocity field.

The pre-stack CMP gathers are sorted according to the various trial geometries in Table 1, and the prestack time migration is processed and analyzed.

\subsection{Degradation Processing Effect Analysis}

\subsubsection{Comparison of Different Bin Size Effect with the Same Fold}

The data were compared with fold 256 (geometries S0 and S1 of Table 1). From the PSTM profiles (Figure 3), compared with the profile with large bin size and low trace density, the profile with small bin size and high trace density has 


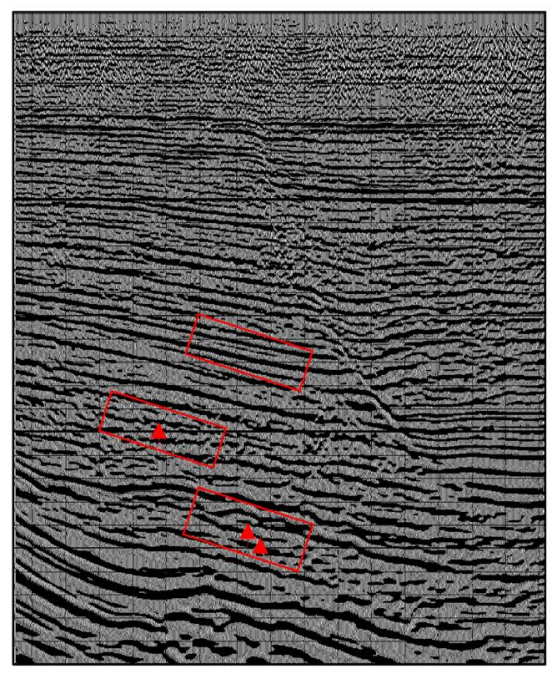

(a)

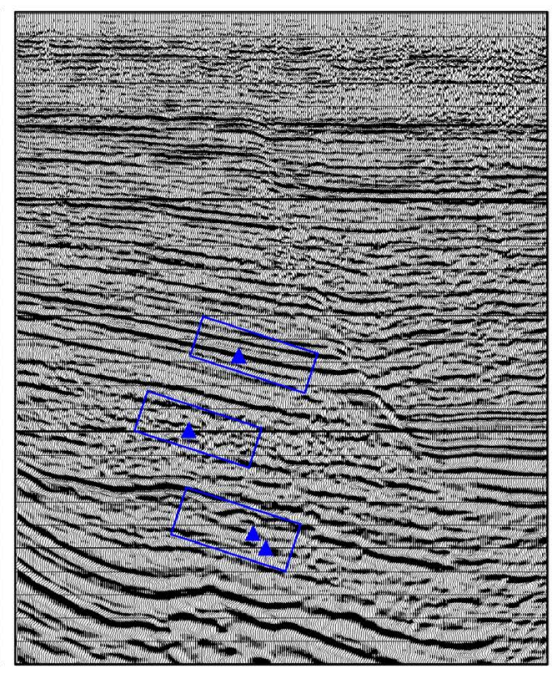

(b)

Figure 3. PSTM profiles of bin size $10 \mathrm{~m} \times 10 \mathrm{~m}$ (a) and $20 \mathrm{~m} \times 20 \mathrm{~m}$ (b) with fold 256 .

obviously higher SNR and resolution, and has better continuity for interlayer weak reflection and steep dip layer.

From the PSTM time slices at $2.5 \mathrm{~s}$ (Figure 4), compared with the time slice with large bin size and low trace density, the time slice with small bin size and high trace density has obviously higher SNR in the plane, stronger fault recognition ability, better seismic event continuity (as indicated by ellipses in the Figure 2.4-2), better lateral resolution (as indicated by arrows in the figure).

From the PSTM amplitude slices along the layer $\mathrm{Es}_{32}$ (Figure 5), compared with the amplitude slices along the layer with large bin size and low trace density, the amplitude slices along the layer with small bin size and high trace density has obviously higher SNR in the plane, better seismic event continuity (as indicated by ellipses in the Figure 5), better lateral resolution of the geological body.

From the PSTM coherent slices (Figure 6), compared with the coherent slice with large bin size and low trace density, the coherent slice with small bin size and high trace density has obviously higher SNR, clearer fault characterization, more reasonable for fracture distribution.

In addition, the PSTM profiles of $10 \mathrm{~m} \times 10 \mathrm{~m}, 20 \times 10 \mathrm{~m}$ and $30 \times 10 \mathrm{~m}$ are compared and analyzed. Based on the analysis of the well data, for bin size $10 \mathrm{~m}$ $\times 10 \mathrm{~m}$ and $20 \mathrm{~m} \times 10 \mathrm{~m}$, the continuity of the carbonatite thin layer of Du3 and gaosheng oil group is equivalent, and the lateral resolution is also equivalent (as shown in Figure 7). For bin size $30 \mathrm{~m} \times 10 \mathrm{~m}$, the continuity and the lateral resolution of the thin layer decreased obviously. For bin size $10 \mathrm{~m} \times 10 \mathrm{~m}$ when the area is $10 \mathrm{~m} \times 10 \mathrm{~m}$, the super-geological phenomena at the bottom of buried hills is clear. When the dome is $20 \mathrm{~m} \times 10 \mathrm{~m}$ and the area is $30 \mathrm{~m} \times 10 \mathrm{~m}$, the interpretation of the buried hilltop will appear. This further shows that the smaller bin size can improve the thin layer resolution and breakpoint recognition accuracy.

According to the above analysis, considering the influence of cost, the bin size 


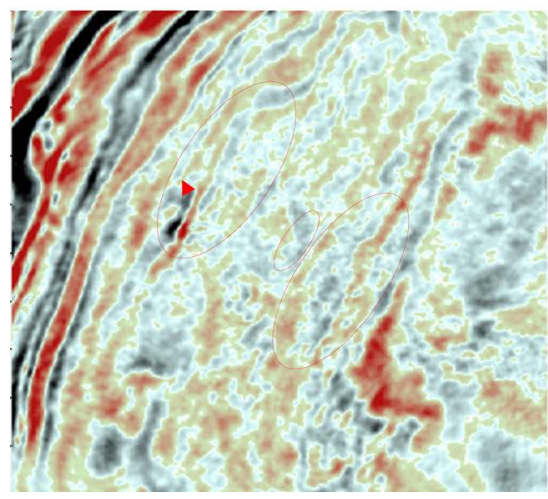

(a)

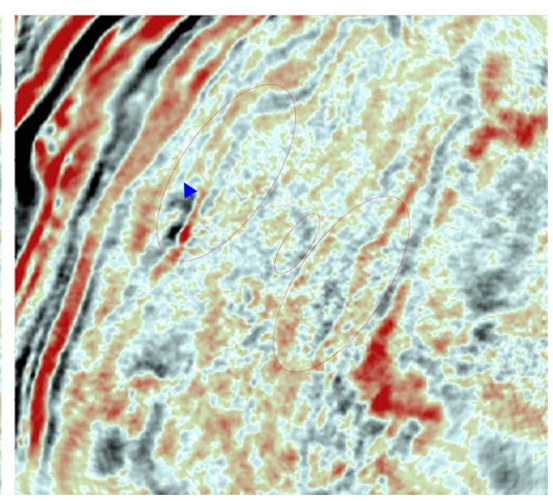

(b)

Figure 4. PSTM time slices of bin size $10 \mathrm{~m} \times 10 \mathrm{~m}$ (a) and $20 \mathrm{~m} \times 20 \mathrm{~m}$ (b) with fold 256.

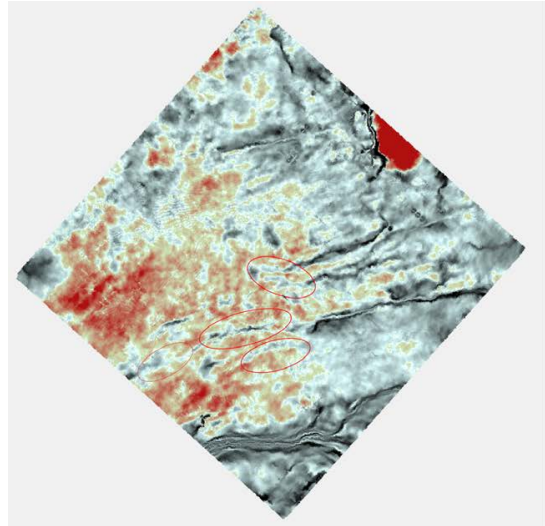

(a)

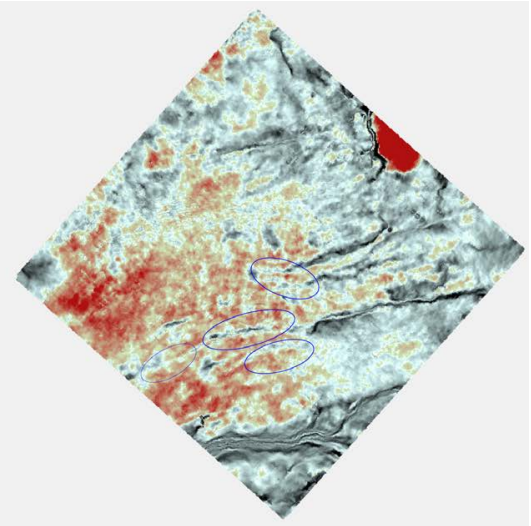

(b)

Figure 5. PSTM amplitude slices along the layer (Es32) of bin size $10 \mathrm{~m} \times 10 \mathrm{~m}$ (a) and 20 $\mathrm{m} \times 20 \mathrm{~m}$ (b) with fold 256 .

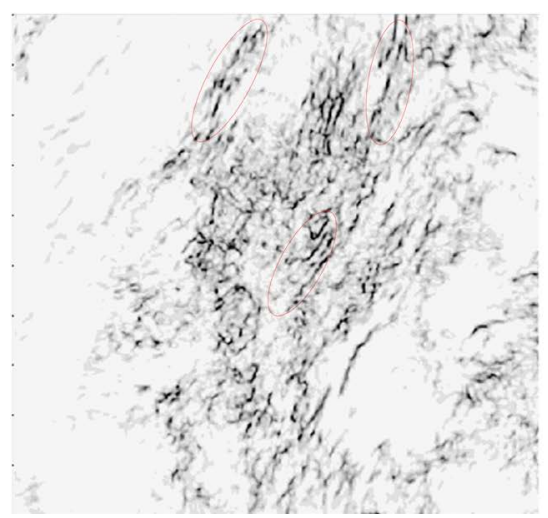

(a)

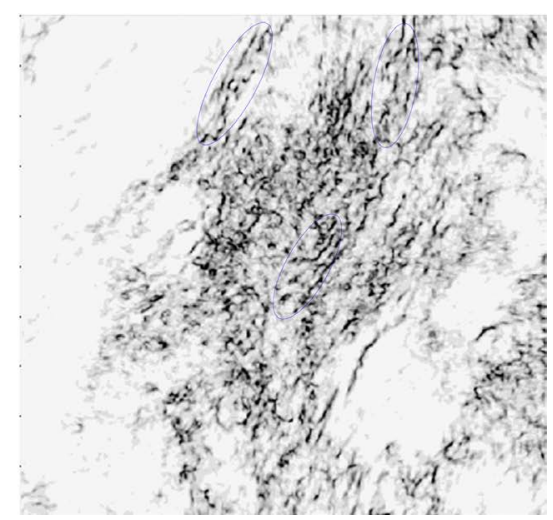

(b)

Figure 6. PSTM coherent slices of bin size $10 \mathrm{~m} \times 10 \mathrm{~m}$ (a) and $20 \mathrm{~m} \times 20 \mathrm{~m}$ (b) with fold 256.

$10 \mathrm{~m} \times 10 \mathrm{~m}$ surface can be weakened appropriately in meeting the requirements of geological task. In the Liaohe Depression, the bin size of the second three-dimensional acquisition is $25 \mathrm{~m} \times 25 \mathrm{~m}$, and it is suggested to optimize the 


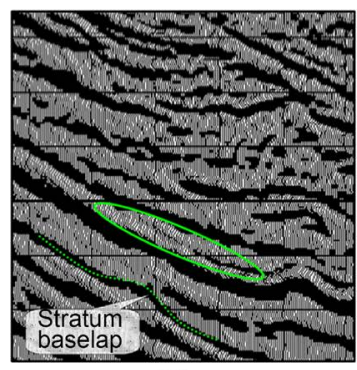

(a)

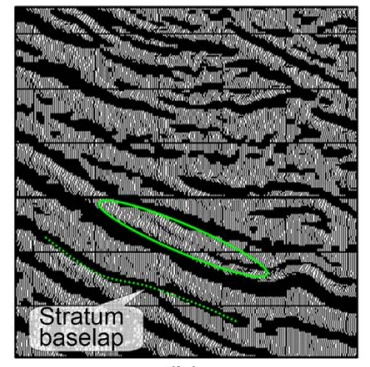

(b)

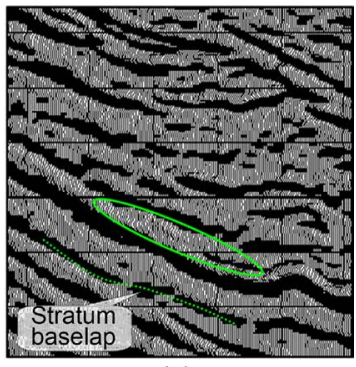

(c)

Figure 7. Localgraph of the prestack time migration section of different bin sizes (a) $10 \mathrm{~m}$ $\times 10 \mathrm{~m}$; (b) $20 \mathrm{~m} \times 10 \mathrm{~m}$; (c) $30 \mathrm{~m} \times 10 \mathrm{~m}$.

bin $10 \mathrm{~m} \times 10 \mathrm{~m}$ to $12.5 \mathrm{~m} \times 12.5 \mathrm{~m}$ from the new and old data fusion.

\subsubsection{Comparison of Different Fold Effect with the Same Bin Size}

The comparison and analysis of prestack time migration is carried out using three dataset of different folds and trace densities with the same bin size $10 \mathrm{~m} \times$ $10 \mathrm{~m}$ (geometries S0, S2 and S3 in Table 1).

Figure 8 shows prestack time migration profiles of fold 256, 128, and 64. When the fold reduced from 256 to 128, the signal-to-noise ratio of the target layer Es4 decreased a little, the continuity of seismic event became worse and the lateral resolution decreased a little. When the fold is further reduced to 64 , the signal-to-noise ratio of the target layer Es4 decreased obviously, the seismic event became disordered, and the lateral resolution is significantly reduced obviously.

Figure 9 shows time slices of fold 256, 128, and 64. When the fold reduced from 256 to 128, the signal-to-noise ratio of the target layer Es4 decreased a little, the continuity of seismic event became worse and the lateral resolution decreased a little. When the fold is further reduced to 64 , the signal-to-noise ratio of the target layer Es4 decreased obviously, the seismic event became disordered, and the lateral resolution is significantly obviously.

Figure 10 shows amplitude slices (Es32) of fold 256, 128, and 64. When the fold reduced from 256 to 128, the signal-to-noise ratio of the target layer Es4 decreased a little, the fault recognition ability reduced a little. When the fold is further reduced to 64, the signal-to-noise ratio of the target layer Es4 decreased obviously, Clearness of the fault was reduced obviously.

Figure 11 shows PSTM coherent slices of fold 256, 128, and 64. When the fold reduced from 256 to 128, the signal-to-noise ratio of the target layer Es4 decreased a little, the fault recognition ability reduced a little. When the fold is further reduced to 64, the signal-to-noise ratio of the target layer Es4 decreased obviously, clearness of the fault was reduced obviously.

According to the above analysis, in order to meet the requirements of geological task, considering the influence of cost, the fold can be reduced on the basis of 256, but higher than 128 .

\subsubsection{Comparison of Big Bin Size and High Fold with Small Bin Size and Low Fold}

Under the condition of the trace density as $640,000 / \mathrm{km}^{2}$, the comparison and 


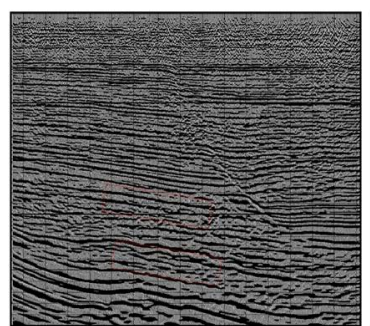

(a)

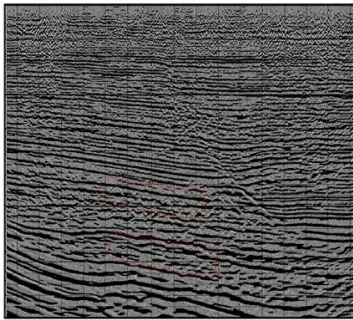

(b)

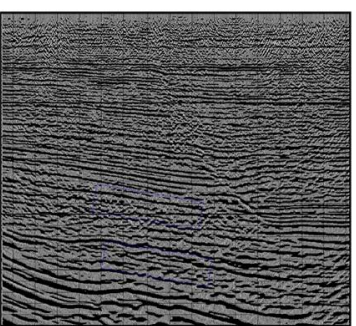

(c)

Figure 8. PSTM profiles of different folds 256 (a), 128 (b), 64 (c) with the same bin size $10 \mathrm{~m} \times 10 \mathrm{~m}$.

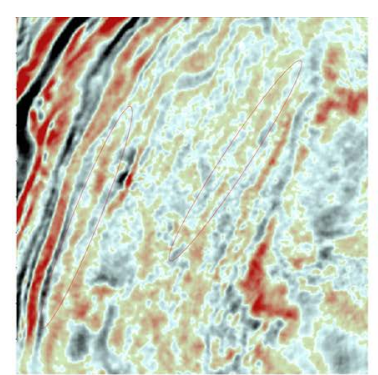

(a)

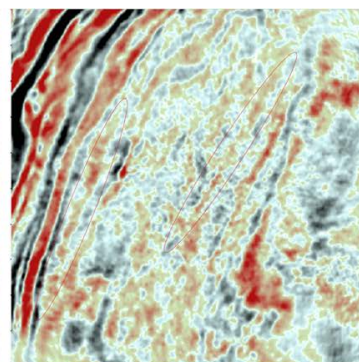

(b)

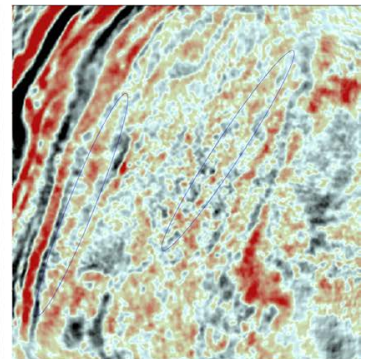

(c)

Figure 9. PSTM time slices of different folds 256 (a), 128 (b), 64 (c) with the same bin size $10 \mathrm{~m} \times 10 \mathrm{~m}$.

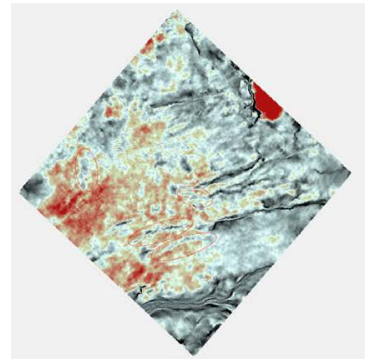

(a)

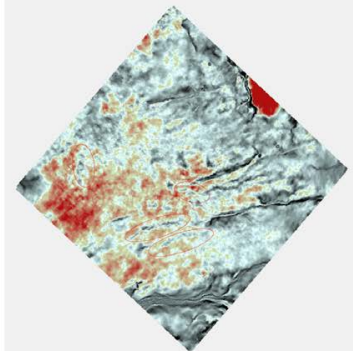

(b)

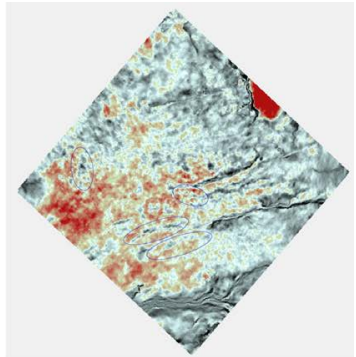

(c)

Figure 10. PSTM amplitude slices along the layer (Es32) of different folds 256 (a), 128 (b), 64 (c) with the same bin size $10 \mathrm{~m} \times 10 \mathrm{~m}$.

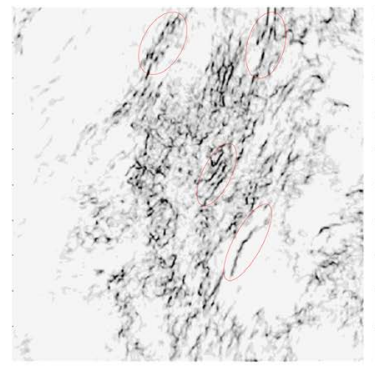

(a)

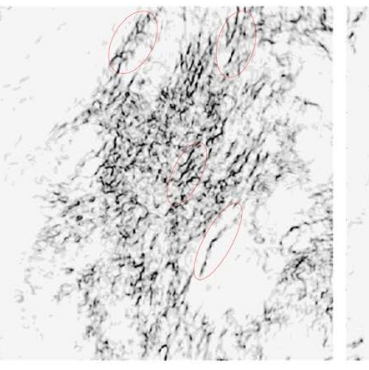

(b)

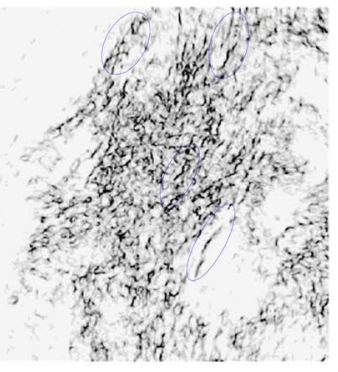

(c)

Figure 11. PSTM coherent slices of different folds 256 (a), 128 (b), 64 (c) with the same bin size $10 \mathrm{~m} \times 10 \mathrm{~m}$.

analysis of prestack time migration is carried out using two datasets (geometries 
S1 and S3 in Table 2.4-1) of big bin size $(20 \mathrm{~m} \times 20 \mathrm{~m}) \&$ high fold $(256)$ and small bin size $(10 \mathrm{~m} \times 10 \mathrm{~m}) \&$ low fold (64).

From the PSTM profiles (Figure 12), compared with the profile with small bin size $(10 \mathrm{~m} \times 10 \mathrm{~m}) \&$ low fold (64), the profile with big bin size $(20 \mathrm{~m} \times 20$ m) \& high fold (256) has higher signal to noise ratio than the profile with small bin size $(10 \mathrm{~m} \times 10 \mathrm{~m})$ \& low fold (64).

From the PSTM time slices at $2.5 \mathrm{~s}$ (Figure 13), compared with the profile with small bin size $(10 \mathrm{~m} \times 10 \mathrm{~m})$ \& low fold (64), the profile with big bin size $(20 \mathrm{~m} \times 20 \mathrm{~m}) \&$ high fold (256) has higher signal to noise ratio, better seismic event continuity (as indicated by ellipses in Figure 13).

From the PSTM amplitude slices of Es32 (Figure 14), compared with the profile with small bin size $(10 \mathrm{~m} \times 10 \mathrm{~m})$ \& low fold (64), the profile with big bin size $(20 \mathrm{~m} \times 20 \mathrm{~m}) \&$ high fold $(256)$ has higher signal to noise ratio, better seismic event continuity (as indicated by ellipses in Figure 14).

From the PSTM coherent slices (Figure 15), compared with the profile with small bin size $(10 \mathrm{~m} \times 10 \mathrm{~m}) \&$ low fold $(64)$, the profile with big bin size $(20 \mathrm{~m}$

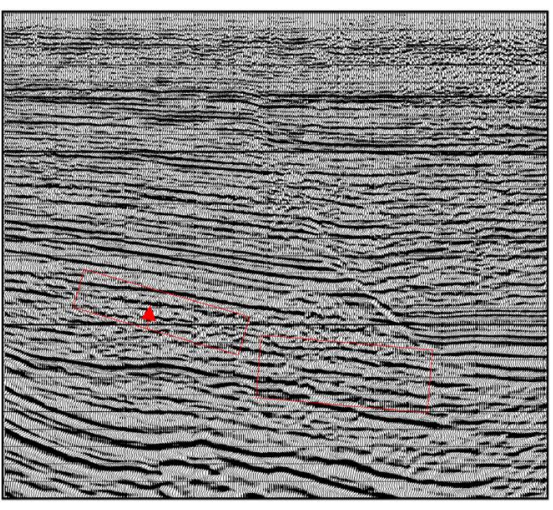

(a)

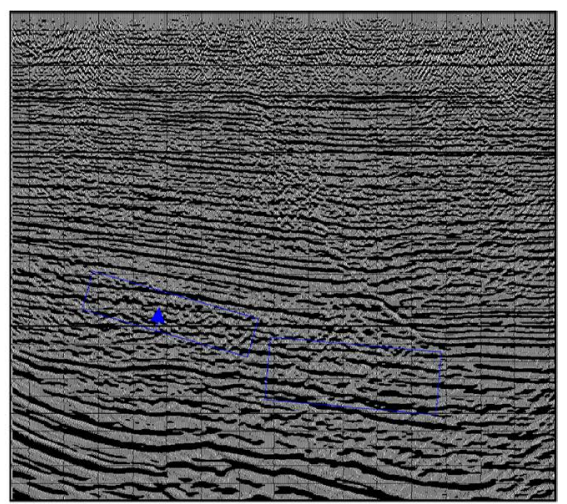

(b)

Figure 12. PSTM profiles of different bin size and fold bin size $20 \mathrm{~m} \times 20 \mathrm{~m} \&$ fold 256 (a), bin size $10 \mathrm{~m} \times 10 \mathrm{~m} \&$ fold 64 (b).

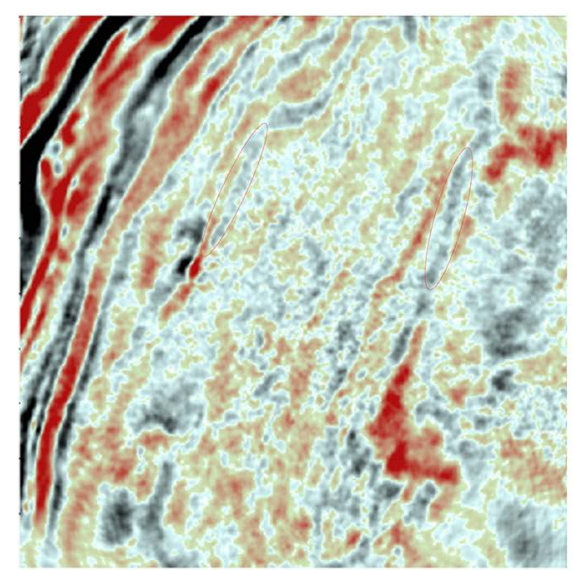

(a)

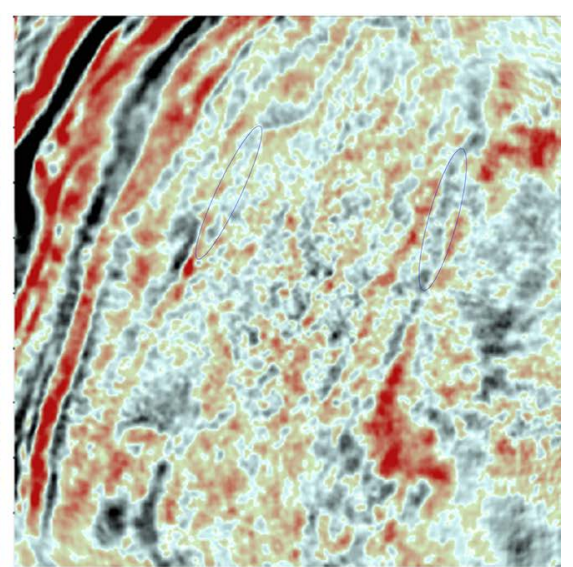

(b)

Figure 13. PSTM time slices of different bin size and fold, bin size $20 \mathrm{~m} \times 20 \mathrm{~m} \&$ fold 256 (a), bin size $10 \mathrm{~m} \times 10 \mathrm{~m} \&$ fold 64 (b). 


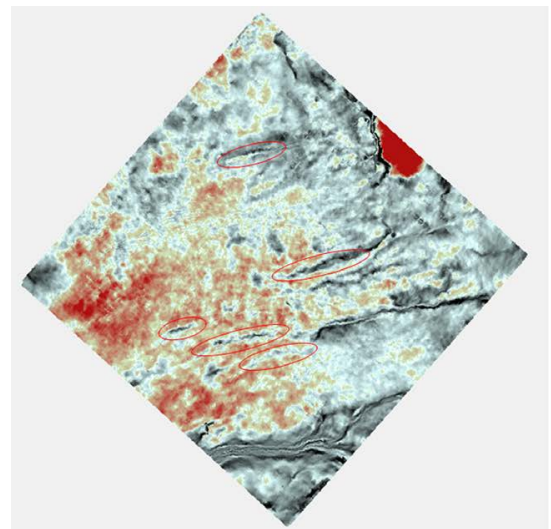

(a)

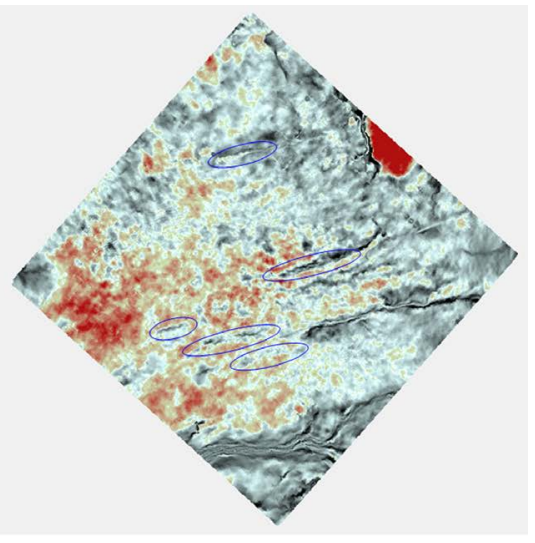

(b)

Figure 14. PSTM amplitude slices along the layer (Es32) of different bin size and fold, bin size $20 \mathrm{~m} \times 20 \mathrm{~m} \&$ fold 256 (a), bin size $10 \mathrm{~m} \times 10 \mathrm{~m} \&$ fold 64 (b).

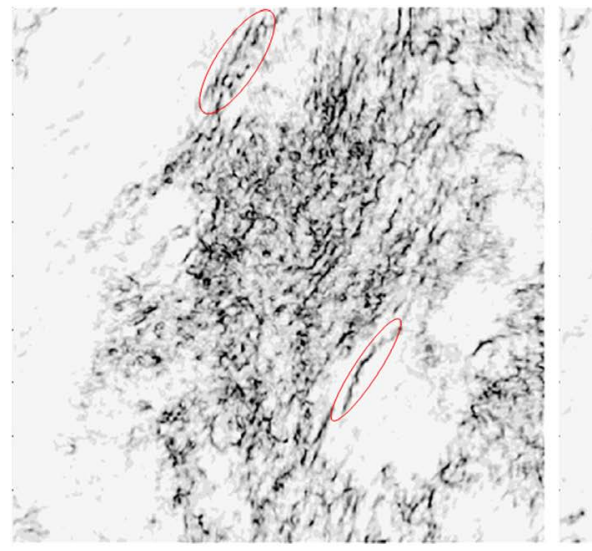

(a)

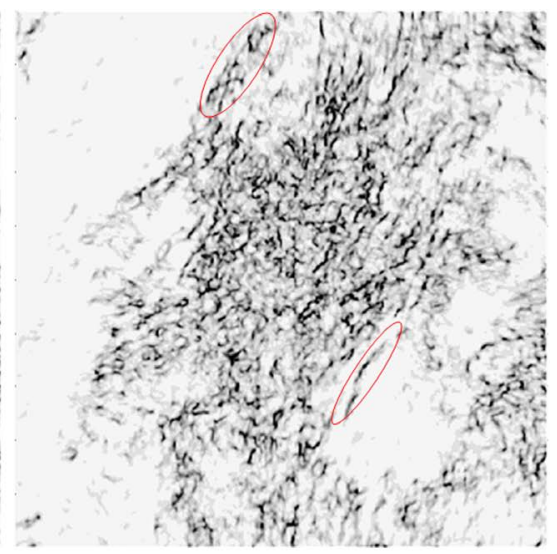

(b)

Figure 15. PSTM coherent slices along the layer (Es32) of different bin size and fold bin size $20 \mathrm{~m} \times 20 \mathrm{~m} \&$ fold 256 (a), bin size $10 \mathrm{~m} \times 10 \mathrm{~m} \&$ fold 64 (b).

$\times 20 \mathrm{~m}$ ) \& high fold (256) has higher signal to noise ratio, better seismic event continuity (as indicated by ellipses in the Figure 15).

\subsubsection{Comparison of Different Aspect Ratio with the Same Bin Size}

The comparison and analysis of prestack time migration is carried out using three datasets of different aspect ratio $0.91,0.80$ and 0.51 with the same bin size $10 \mathrm{~m} \times 10 \mathrm{~m}$ (geometries S0, S4 and S5 in Table 1).

Figure 16 shows prestack time migration profiles of different aspect ratio $0.91,0.80$, and 0.51 . With the increase of the aspect ratio, the breakpoint imaging is gradually improved, and the deep signal-to-noise ratio is also improved.

Figure 17 shows time slices of aspect ratio $0.91,0.80$, and 0.51 . The difference is small between the data of wide azimuth (aspect ratio 0.91, 0.80). Compared with the profile with narrower azimuth (aspect ratio 0.51 ), the data of wide azimuth (aspect ratio $0.91,0.80$ ) has higher signal to noise ratio and better seismic event continuity.

Figure 18 shows amplitude slices (Es32) of aspect ratio $0.91,0.80$, and 0.51 . 
The difference is small between the data of wide azimuth (aspect ratio 0.91, 0.80 ). Compared with the profile with narrower azimuth (aspect ratio 0.51), the data of wide azimuth (aspect ratio $0.91,0.80$ ) has higher signal to noise ratio and better seismic event continuity.

Figure 19 shows PSTM coherent slices of different aspect ratio 0.91, 0.80, and 0.51 . The difference is small between the data of wide azimuth (aspect ratio $0.91,0.80$ ). Compared with the profile with narrower azimuth(aspect ratio 0.51), the data of wide azimuth (aspect ratio $0.91,0.80$ ) has better thin layer continuity, better fault continuity and better fault identification ability.

\subsubsection{Comparison of Different Shot Line Interval with the Same Bin Size and Fold}

The comparison and analysis of prestack time migration is carried out using two

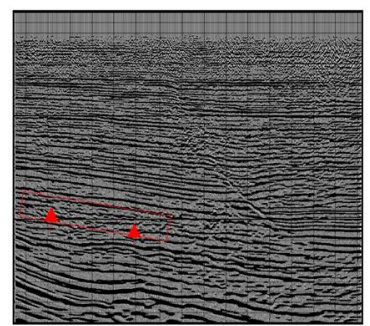

(a)

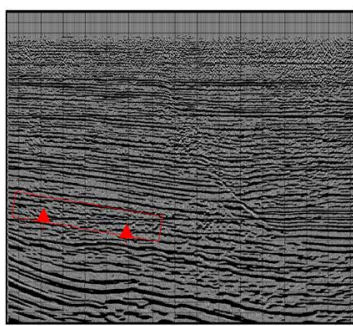

(b)

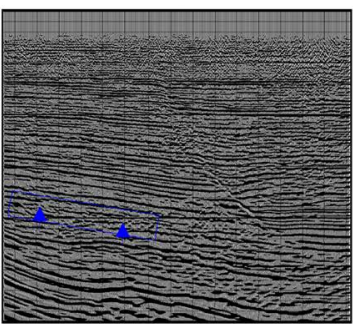

(c)

Figure 16. PSTM profiles of different aspect ratio with the same bin size $10 \mathrm{~m} \times 10 \mathrm{~m}$ 0.91 (a), 0.80 (b), 0.51 (c).

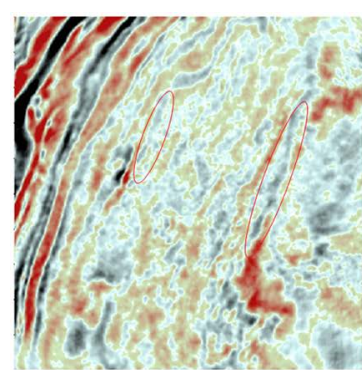

(a)

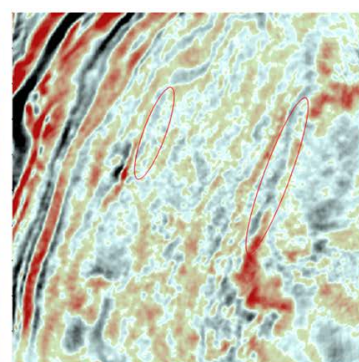

(b)

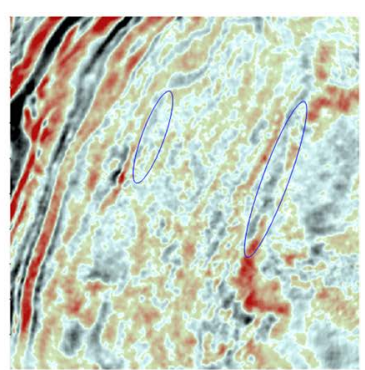

(c)

Figure 17. PSTM time slices of different aspect ratio with the same bin size $10 \mathrm{~m} \times 10 \mathrm{~m}$ $0.91(\mathrm{a}), 0.80$ (b), 0.51 (c).

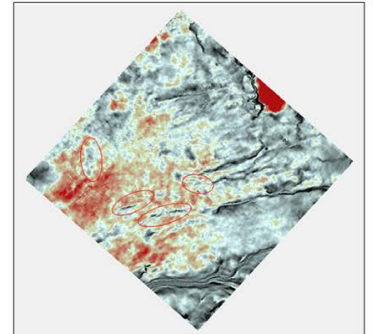

(a)

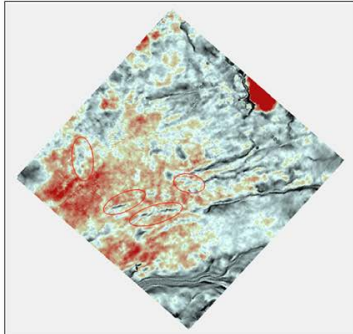

(b)

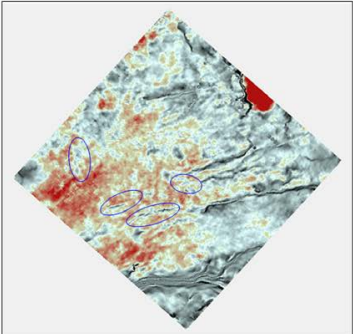

(c)

Figure 18. PSTM amplitude slices along the layer (Es32) of different aspect ratio with the same bin size $10 \mathrm{~m} \times 10 \mathrm{~m} 0.91$ (a), 0.80 (b), 0.51 (c). 


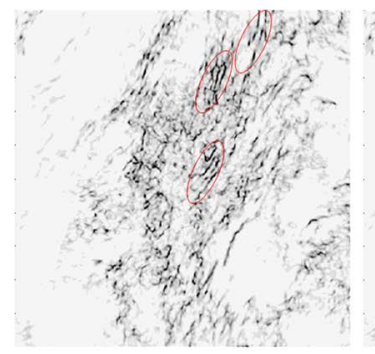

(a)

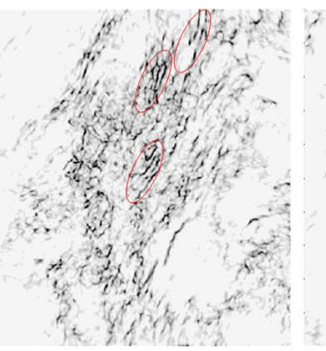

(b)

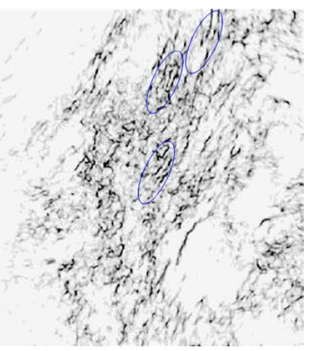

(c)

Figure 19. PSTM coherent slices of different aspect ratio with the same bin size $10 \mathrm{~m} \times 10$ m 0.91 (a), 0.80 (b), 0.51 (c).

datasets (geometries S2 and S5 in Table 1), which has the same bin size $10 \mathrm{~m} \times$ $10 \mathrm{~m}$, the same fold and the same trace density, but different shot line interval (440 $\mathrm{m}$ and $220 \mathrm{~m}$ ).

For the survey with the same fold, the fold of the middle-shallow Layer is high for the survey with small line interval, the distribution of middle-shallow layer fold is uniform, and the footprint is weak. For the survey with large line interval, the distribution of middle-shallow layer fold is uneven and it will produce a significant acquisition footprint.

Figure 20 shows prestack time migration profiles of shot interval $440 \mathrm{~m}, 220$ $\mathrm{m}$. For the survey with shot line interval $440 \mathrm{~m}$, the noise of middle-shallow Layer is serious, and the acquisition footprint is obvious, the signal to noise ratio of deep layer is low, but for the survey with shot line interval $220 \mathrm{~m}$, the signal to noise ratio of middle-shallow Layer is high, the acquisition footprint is weak, the signal to noise ratio of deep layer is high, the seismic event continuity is good.

Figure 21 shows time slices of different line intervals. For the survey with small shot line interval $(220 \mathrm{~m})$, the signal to noise ratio is high, and the amplitude attribute is uniform, but for the survey with big shot line interval (440 m), seismic event continuity is interrupted significantly, the amplitude attribute uniformity is poor, and this is caused by acquisition footprints.

Figure 22 shows amplitude slices of Es32 of different line intervals. For the survey with small shot line interval $(220 \mathrm{~m})$, the signal to noise ratio is high, the seismic event is clear and the seismic event continuity is good, but for the survey with big shot line interval $(440 \mathrm{~m})$, data acquisition footprints is serious.

Figure 23 shows PSTM coherent slices at $2.5 \mathrm{~s}$. Compared with the coherent slice with big line interval (shot line interval $440 \mathrm{~m}$ ), the coherent slice with small line interval (shot line interval $220 \mathrm{~m}$ ) has better noise suppression effect, more clear fault imaging.

In order to ensure the amplitude attribute fidelity and uniformity and improve the accuracy of reservoir prediction, we should adopt a smaller line interval to minimize the impact of the acquisition footprint on the data.

\section{Effect of the Seismic Data}

Based on the above research, the optimization direction of high precision seismic in Liaohe depression is determined, which provide guidance for the 
establish of the following 3D seismic acquisition geometry. HX 3D acquisition adopted the suggested geometry parameters proposed in this paper, bin size: $12.5 \mathrm{~m} \times 12.5 \mathrm{~m}$, fold: 396 (shooting with vibroseis, and the fold is twice over shooting with charge), receiver line interval/shot line interval: $200 \mathrm{~m} / 200 \mathrm{~m}$, aspect ratio: 0.82 , and achieved good results. The signal-to-noise ratio of new

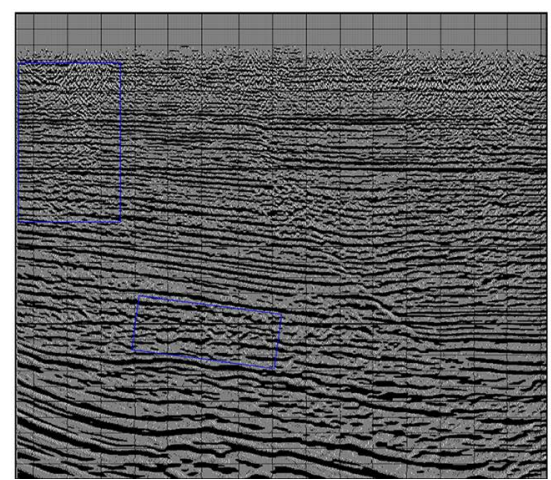

(a)

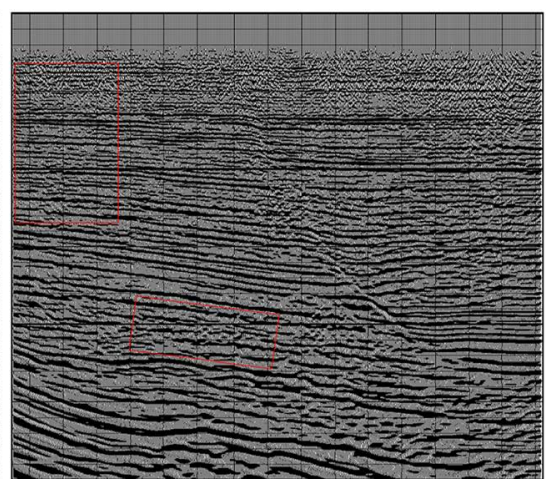

(b)

Figure 20. PSTM profiles of different shot line interval $440 \mathrm{~m}$ (a), 220 (b).

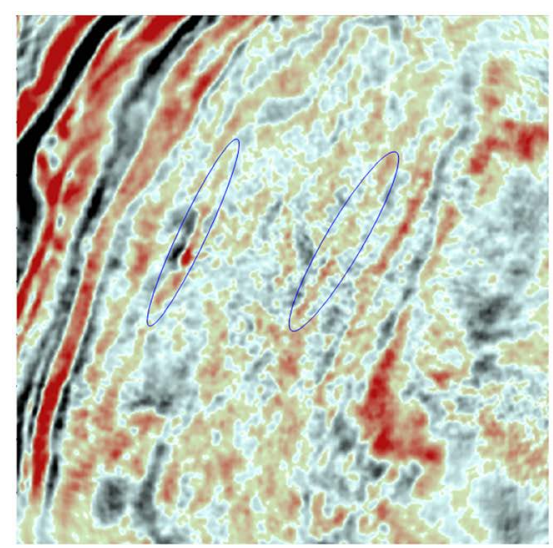

(a)

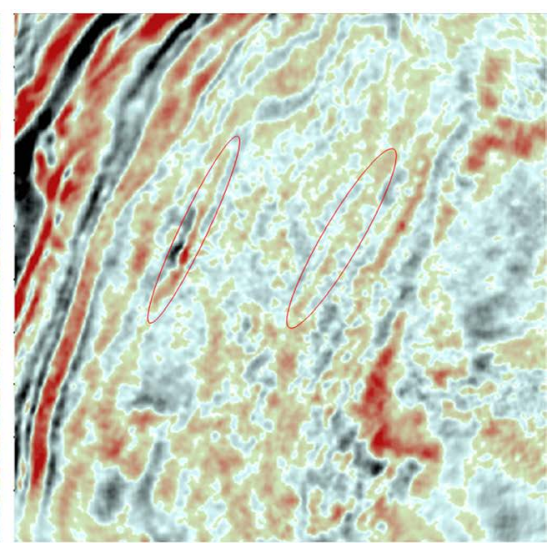

(b)

Figure 21. PSTM time slices of different shot line interval $440 \mathrm{~m}$ (a), $220 \mathrm{~m}$ (b).

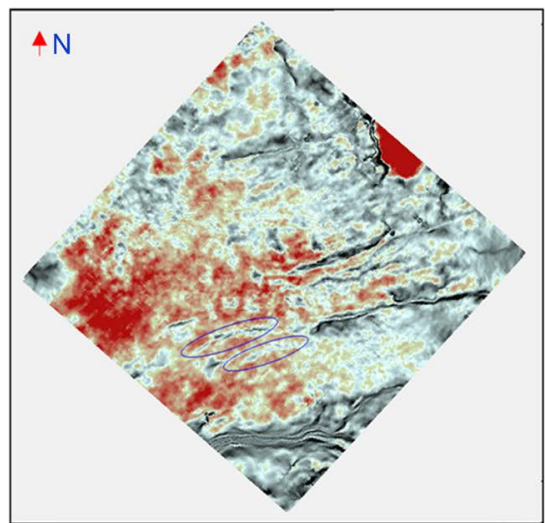

(a)

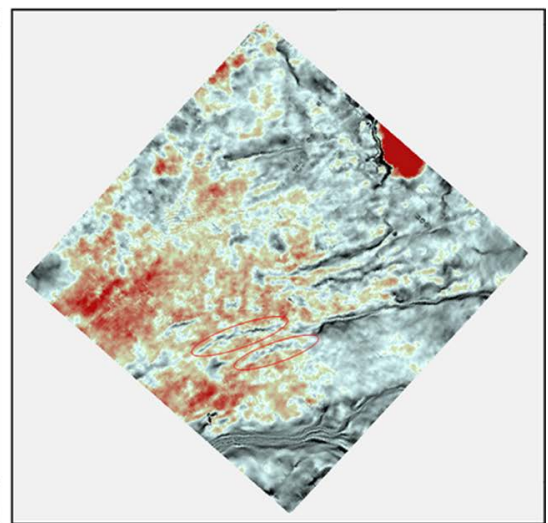

(b)

Figure 22. PSTM amplitude slices along the layer (Es32) of different shot line interval 440 $\mathrm{m}(\mathrm{a}), 220 \mathrm{~m}$ (b). 
acquisition high precision $3 \mathrm{D}$ data is high, and the resolution is improved obviously [13]. For the new acquisition data, it is blank weak reflection on west side of Jia Zhang Si fault, and is disorder reflection on the east side of Jia Zhang $\mathrm{Si}$ fault, further confirmed on both sides of the fault have the characteristics of lithology mutation. For the old data, it is disorder reflection on both sides of Jia Zhang Si fault, which does not reflect lithology mutations (Figure 24).

\section{Conclusions}

Theoretically, the higher the fold, the smaller the bin size, and the higher the trace density, the better the seismic data quality. In fact, optimizing the cost-effective acquisition parameters under the premise of meet the requirements of geological tasks, is an important objective of geometry parameter optimization. Comprehensive consideration of thin-layer identification, fault imaging and reduce the acquisition cost, the geometry parameters are recommended as follows: bin size: $12.5 \mathrm{~m} \times 12.5 \mathrm{~m}$, fold: 200 , aspect ratio: more than 0.80 . The above recommended parameters are validated in the other $3 \mathrm{D}$

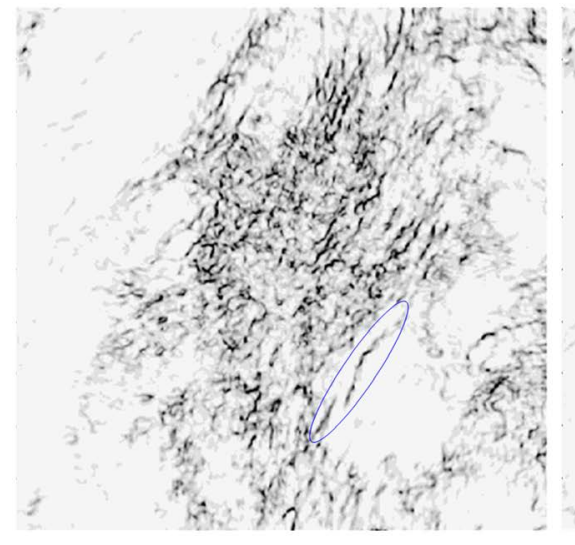

(a)

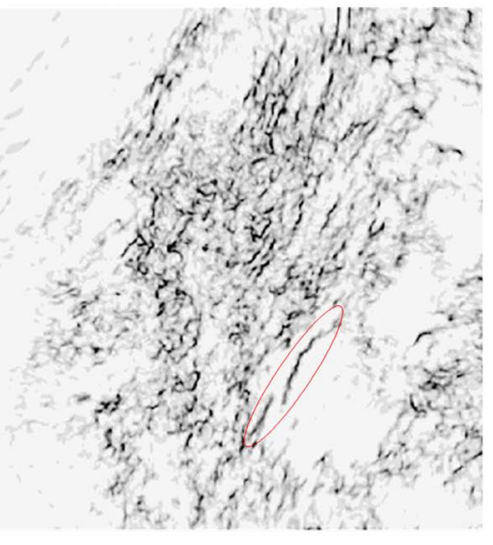

(b)

Figure 23. PSTM coherent slices of different shot line interval $440 \mathrm{~m}$ (a), $220 \mathrm{~m}$ (b).

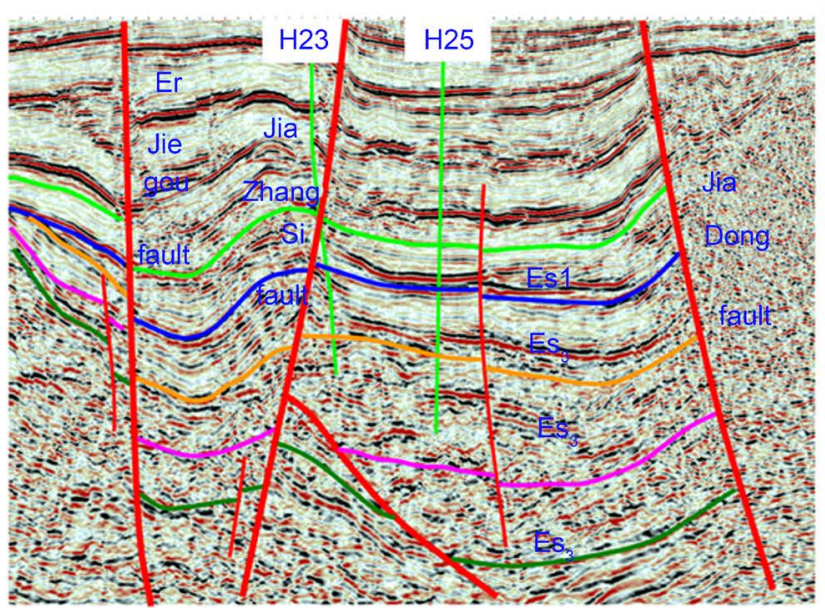

(a)

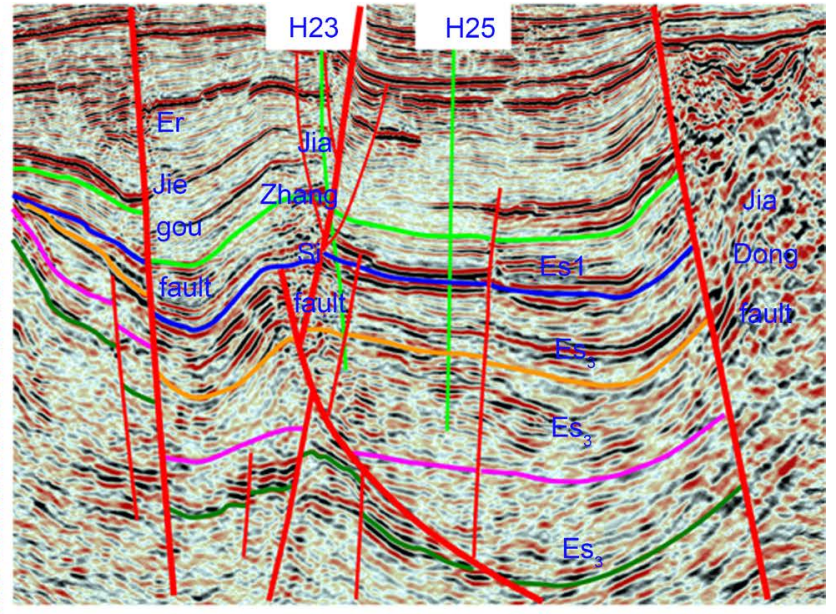

(b)

Figure 24. Conventional 3D acquisition profile (a) and high precision 3D prestack migration spectrum (b). 
acquisition area in Liaohe depression.

Based on the high precision $3 \mathrm{D}$ acquisition data, degradation processing and comparative analysis are the effective means to optimize the geometry parameters. And the best observation system parameters can be found to meet the geological task requirements and reduce the cost. The method is also suitable for other regions.

\section{References}

[1] Wang, X.J., Yu, B.L., Zhao, X.H., et al. (2015) Development and Application of "2W1H" Technique in Oil and Gas Exploration. China Petroleum Exploration, 20, 41-53.

[2] Kong, D.Z., Yu, M.J., Liu, X.W., et al. (2016) Application and Effects of the "TwoWide One-High" Seismic Acquisition Technique in Complex Piedmont. Xinjiang ShiYou TianRan Qi, 12, 33-38.

[3] Li, P.M., Kang, N.C., Zou, X.F., et al. (2013) The Key Technology of High Precision Seismic Exploration in “Two-Wide One-High” High Precision Seismic Exploration. Memoir of 2013 China Geophysical Nineteenth Sub Assembly Hall. Petroleum Industry Press, Beijing.

[4] Zhang, B.Q., Jin, S.T., Zeng, T.J., et al. (2015) Application of "Two High and One Wide" Seismic Exploration Technology in the Eastern Margin of the Caspian Sea Basin. China Petroleum Institute Geophysical Technology Conference, 82-85.

[5] Wang, H.B., Liu, Y.K. and Zou, Q.W. (2016) Single Point High Density 3D Seismic Acquisition Technical Studies in Leijia Tight Sandstone Oil Reservoir of Liaohe Depression. Progress in Geophysics, 31, 0782-0787. (In Chinese)

[6] Wloszczowski, D., Gou, Y. and Faraj, A. (1998) 3D Acquisition Parameters: A CostSaving Study. Expanded Abstracts of 68th Annual International SEG Mtg, 70-73.

[7] Pecholcs, P.I., Zhang, Y. and Lafon, S.K. (2010) Distance Separated Custom SlipSweep-A New High-Productivity Method. Eage Workshop on Developments in Land Seismic Acquisition for Exploration, 41-53.

[8] Ling, Y., Gao, J., Sun, D.S., et al. (2005) Analysis and Appreciation of Wide/Narrow Azimuth Exploration Cases (1). OGP, 40, 305-308, 317.

[9] Ling, Y., et al. (2005) Analysis and Appreciation of Wide/Narrow Azimuth Exploration Cases(II). Oil Geophysical Prospecting, 40, 423-427.

[10] Wei, Z., Yin, C., Tian, J.D., et al. (2007) Degradation Processing Experiment Based on 3-D Geometry Parameters. CPP, 46, 69-73.

[11] Xu, Y. (2014) Optimization on the High-Precision 3D Seismic Acquisition Parameters in Tahe Oilfield. Geophysical Prospecting for Petroleum, 1, 68-77.

[12] Zhu, Y.H., Chen, X.Q. and Wang, N.J. (2015) Optimization of High Precision 3D Seismic Acquisition Geometry in Tazhong Oilfield. China Petroleum Institute Geophysical Technology Conference, 105-108.

[13] Wang, H.B., Liu, B., Zou, Q.W., et al. (2016) 3D Seismic Acquisition Technology and Effect in HX Volcanic Area in Liaohe Depression. International Journal of Geosciences, 7, 944-955. 
Submit or recommend next manuscript to SCIRP and we will provide best service for you:

Accepting pre-submission inquiries through Email, Facebook, LinkedIn, Twitter, etc. A wide selection of journals (inclusive of 9 subjects, more than 200 journals)

Providing 24-hour high-quality service

User-friendly online submission system

Fair and swift peer-review system

Efficient typesetting and proofreading procedure

Display of the result of downloads and visits, as well as the number of cited articles Maximum dissemination of your research work

Submit your manuscript at: http://papersubmission.scirp.org/

Or contact ijg@scirp.org 